Original Research Paper

\title{
Improving the Approaches to Planning the Electricity Consumption in Budget Institutions
}

\author{
Nailya Malikovna Yakupova, Rezeda Muhtarovna Kundakchyan, \\ Roza Nuriahmetovna Andreeva and Aleksey Vladimirovich Andreev
}

The Institute of Management, Economics and Finance, Kazan (Volga region) Federal University, Kazan, Russia

\author{
Article history \\ Received: 08-11-2015 \\ Revised: $23-11-2015$ \\ Accepted: 25-11-2015 \\ Corresponding Author: \\ Aleksey Vladimirovich \\ Andreev \\ The Institute of Management, \\ Economics and Finance, Kazan \\ (Volga region) Federal \\ University, Kazan, Russia \\ Email: Aleksey_Andreev_mail@mail.ru
}

\section{Introduction}

One of the topical trends in the modern economy is increasing the energy efficiency and efficacy of energy carriers' utilization. An essential contribution to both the methodological and applied aspects of estimating the level of energy carriers' utilization has been made by the Western scholars. For example, Florax et al. (2011; Kai, 1999; Lee and Stephen, 1992; Suehiro, 2007; Sgroi et al., 2014; Tudisca et al., 2013) highlighted the energy consumption of GDP as the main criteria reflecting the energy efficiency of economy.

The research of the parameters of energy carriers' consumption (EIA, 2014; David and Ivan, 2012) allows to conclude that both in Russia and other world leading economies, the main energy carriers' consumer is the real sector of economy. However, it should be noted that the state does not possess the efficient enough tools of direct influence on the energy consumption of the real sector, which is mainly composed of private companies, but can influence the energy consumption of the state authorities' institutions. As it is, the Russian government has defined the budget sector as a demo platform to set an example of reducing energy consumption. Besides, it should be noted that the budget sector, as well as the real sector of economy, is very energy consuming. Even in the countries, which show the best examples of GDP energy consumption, the budget sector is considered to be energy consuming. For example, in the USA some educational institutions were declared energy wasteful (Winnie, 2011).

A similar phenomenon can be observed in the subjects of the Russian Federation, too. Thus, it is certain academic interest to study the conditions (factors) influencing the energy consumption in the budget sphere of economy and to reveal the degree and vector of their influence on energy consumption.

\section{Materials and Methods}

The research has been based on the normativelegal acts of the Russian Federation in the sphere of energy saving, the research of the Western scholars and international agencies (IAEA, 2005), as well as the data provided by educational authorities of Spasskiy, Alekseyevskiy, Novosheshmiskiy and 
Chistopolskiy municipal districts of Tatarstan Republic from 2009 till 2013 by months.

During the research, general scientific methods (systemic analysis, synthesis, induction, deduction) and special economic-mathematical methods were used. Each method was used in conformance with its functionality and resolution to solve the appropriate research tasks (Yakupova et al., 2015).

To construct and identify the economic-mathematical model, we studied the example of educational establishments of Spasskiy municipal district.

At the first stage of research, the endogenous and exogenous factors were defined, which influence the electric energy consumption. A scientific hypothesis was suggested that such factors may include:

- Duration of the daylight hours

- Share of educational establishments requiring overhaul, in the total number of educational establishments

- Share of educational establishments equipped with electricity supply meters, in the total number of educational establishments

- Share of educational establishments, with which the energy servicing contracts were signed, in the total number of educational establishments

- Share of educational establishments, in which the energy audit was conducted, in the total number of educational establishments

\section{Results}

The time-series analysis of the unit electricity consumption from January 2009 till December 2013 showed the seasonal character of electrical energy consumption. Thus, in the winter months, the daylight hours are shorter and the unit electricity consumption increases to 2.5-2.8 kilowatt-hour per square meter a month; in summer months the consumption decreases by 1.4-2.1 kilowatt-hour per square meter a month. This allows to state that the econometric model of electricity consumption dependence on endogenous and exogenous factors has a form of multiplicative trend-season model (Osipov and Khrapov, 2002).

To calculate the quantitative characteristics of the seasonal component, we have defined the period of seasonal fluctuations, basing on the analysis of autocorrelation coefficient of n-th order for each month. Calculations showed that for the first order the autocorrelation coefficient was $\mathrm{r} 1=0.8$, for the second order -0.5 , for the third order -0.06 , etc. The largest value of autocorrelation coefficient corresponds to the last month-December (0.9), which allows to consider the periodicity of the seasonal fluctuations of electricity consumption to be equal to 12 months.

According to the technique of trend-season models construction, the corrected seasonal component is calculated basing on the moving average and the centered moving average. In the multiplicative model, the sum of the values of the seasonal component by all months will be equal to the number of periods in a cycle. To meet this requirement, we have defined the correctional coefficient by the analyzed municipal district and done an appropriate correction. The corrected values of the seasonal component by the unit electricity consumption are presented in Table 1 .

Analysis of Table 1 allows to state that there is a certain dynamics of the values of the corrected seasonal component: On the one hand, with the warm season approaching increasing of the daylight hours the seasonal component declines; on the other hand, with the cold period the seasonal component grows.

The next stage of forming the trend-season model is to define the value of trend variable $(\mathrm{T})$, with is the dynamics of electricity consumption, not influenced by the season.

To define the quality of economic-mathematical model, we must check the satisfiability of certain GaussMarkov prerequisites, one of which is the absence of multi-collinearity (Bashirov, 2004; Nazarov, 2000). The study of correlation matrix of exogenous factors has shown that there is multi-collinearity between the duration of daylight hours and the seasonal component. Due to that, we have excluded the factor of "duration of daylight hours" from the further reaserch, as it has a minor impact on the unit electricity consumption.

Further, in order to reveal a "pure" impact of the internal factors on the trend of electricity consumption, we excluded the factor of "season" from the electricity consumption. To define the trend numerical values, we have found a difference between the value of a monthly unit electricity consumption and the value of a seasonal component during the corresponding period.

Table 1. Numerical values of the corrected seasonal component by the electricity consumption for the educational organizations of Spasskiy municipal district of Tatarstan Republic

\begin{tabular}{ll}
\multicolumn{2}{c}{ Tatarstan Republic } \\
& $\begin{array}{l}\text { Numerical values of the } \\
\text { corrected seasonal } \\
\text { component, kilowatt-hour } \\
\text { per square meter a month }\end{array}$ \\
Month & 1.5533 \\
\hline January & 1.5555 \\
February & 1.3187 \\
March & 0.9485 \\
April & 0.6722 \\
May & 0.5167 \\
June & 0.2204 \\
July & 0.3398 \\
August & 0.7574 \\
September & 1.0874 \\
October & 1.3046 \\
November & 1.7256 \\
December & 12.000 \\
Total &
\end{tabular}


The next step of the research is to carry out the correlation analysis to define the closeness of the link between the trend and the internal factors.

For the ease of calculations, we have introduced the following symbols:

- Dependent variable (trend component)-unit electricity consumption, not influenced by the season, (kilowatt-hour per square meter a month)-T

The independent variables were designated as:

- Share of educational establishments requiring overhaul, in the total number of educational establishments-Sh.rep

- Share of budget establishments, in which the energy audit was conducted, in the total number of budget establishments-Sh.audit

- Share of budget establishments, with which the energy servicing contracts were signed, in the total number of budget establishments-Sh.service

- Share of budget establishments equipped with electricity supply meters, in the total number of budget establishments-Sh.device

The preliminary analysis of the data array allowed to exclude such independent variables as: Share of budget establishments equipped with electricity supply meters, in the total number of budget establishments and share of budget establishments, with which the energy servicing contracts were signed, in the total number of budget establishments. The appropriateness of their exclusion is reliably grounded by the fact that the quantitative values of the variables in the analyzed period were constant: Electricity supply meters were installed in all budget establishments of the region ( share $=1$ ), while the energy servicing contracts were not signed ( share $=0$ ).

Table 2 presents of correlation analysis matrix by the other variables.
The data in Table 2 show that the correlation between the unit consumption by a square meter and the independent variables by Chaddock scale (Mkhitaryan, 2005) is characterized as: With the variable Sh.rep-direct high; with the variable Sh.auditreverse marked.

Table 3 shows the results of regression analysis of econometric model of the endogenous and exogenous factors' impact on the unit consumption.

The results of the carried out multi-factor dispersion analysis show the high quality of the obtained model; the included factors explain by $58 \%$ the variation of the dependent variable $\left(\mathrm{R}_{2}=0.580471\right)$. In other words, the model and its parameters are statistically significant with a probability $\mathrm{P}=95 \%$.

Thus, we have constructed a model of dependence of the trend component on the internal environment factors for the educational organizations of Spasskiy municipal district of Tatarstan Republic (Formula 1):

$$
\begin{aligned}
& T=1,164712+2,329121 \\
& \times \text { Sh.rep }-0,294340 \times \text { Sh.audit }+E
\end{aligned}
$$

Where:

$T \quad=$ Unit electricity consumption, not influenced by the season, (kilowatt-hour per square meter a month)

Sh.rep = Share of educational establishments requiring overhaul, in the total number of educational establishments

Sh.audit $=$ Share of educational establishments, in which the energy audit was conducted, in the total number of educational establishments

Table 2. Correlation analysis matrix

\begin{tabular}{lcrr}
\hline & SH_AUDIT & \multicolumn{1}{l}{ T } & \multicolumn{1}{c}{ SH_REP } \\
\hline SH_AUDIT & 1.000000 & -0.610934 & -0.553213 \\
T & -0.610934 & 1.000000 & 0.717197 \\
SH_REP & -0.553213 & 0.717197 & 1.000000 \\
\hline
\end{tabular}

Table 3. Results of regression analysis of econometric model of the electricity consumption

\begin{tabular}{|c|c|c|c|c|}
\hline & Coefficient & Std. Error & t-Statistic & Prob. \\
\hline $\mathrm{C}(1)$ & 1.164712 & 0.171833 & 6.778169 & 0.000000 \\
\hline $\mathrm{C}(2)$ & -0.29434 & 0.099092 & -2.970356 & 0.004400 \\
\hline$C(3)$ & 2.329121 & 0.442847 & 5.259432 & 0.000000 \\
\hline R-squared & 0.580471 & Mean dependent var & & 1.610249 \\
\hline Adjusted R-squared & 0.565487 & S.D. dependent var & & 0.401882 \\
\hline S.E. of regression & 0.264911 & Akaikeinfo criterion & & 0.230662 \\
\hline Sum squared resid & 3.929955 & Schwarz criterion & & 0.336300 \\
\hline Log likelihood & -3.804542 & Hannan-Quinncriter. & & 0.271899 \\
\hline F-statistic & 38.74144 & Durbin-Watsonstat & & 0.747861 \\
\hline Prob(F-statistic) & 0.000000 & & & \\
\hline
\end{tabular}

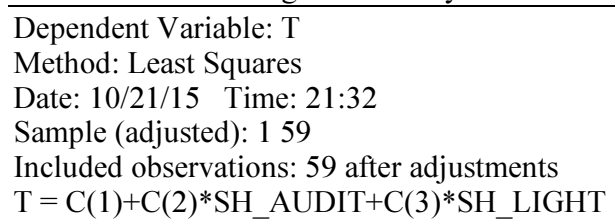


Formula (1) shows that the increase of the share of educational establishments requiring overhaul, in the total number of educational establishments, by 1 percentage point, the unit electricity consumption increases by 2,329121 kilowatt-hour per square meter a month. The increase of the share of educational establishments, in which the energy audit was conducted, in the total number of educational establishments, by 1 percentage point leads, on average, to the decrease of the unit electricity consumption by 0,294340 kilowatt-hour per square meter a month.

Consequently, the trend-season model of the electricity consumption for the educational organizations of Spasskiy municipal district of Tatarstan Republic has the following form (Formula 2):

$$
\mathrm{Y}=\mathrm{S} \times\left(\begin{array}{l}
1.20397+2,24045 \\
\times \text { Sh.rep }-0.3133 \times \text { Sh.audit }
\end{array}\right) \times E
$$

Where:

$Y=$ Unit electricity consumption (kilowatt-hour per square meter a month)

$S=$ Season component

$E=$ Eventual component

\section{Discussion}

On the one hand, defining the normative unit electricity consumption basing on retrospective data is subject to the past errors, i.e., not always efficient electricity consumption in the past. On the other hand, as R.G. Bashirov states, setting the norms without factual data implies a gap between the planned indicators and the real ones. Thus, the normative unit electricity consumption basing on retrospective data should be viewed as one of the methodological principles of norm setting (Bashirov, 2004).

Similar calculation for Novosheshmiskiy, Alekseyevskiy and Chistopolskiy municipal districts of Tatarstan Republic allowed to construct the trend-season models of the electricity consumption in educational organizations (Table 4).

The comparative analysis showed that in the analyzed districts the energy audit did not influence the unit electricity consumption, which is explained by the absence of the variability of the factor "share of educational establishments, in which the energy audit was conducted, in the total number of educational establishments".

Table 4. Trend-season models of the electricity consumption in educational organizations of Chistopolskiy, Alekseyevskiy and Novosheshmiskiy municipal districts of Tatarstan Republic

\begin{tabular}{ll}
\hline $\begin{array}{l}\text { Municipal districts of } \\
\text { Tatarstan Republic }\end{array}$ & Model \\
\hline Chistopolskiy & $\mathrm{y}=\mathrm{S} \times(1.52909+1.147859 \times$ Sh.rep $) \times \mathrm{E}$ \\
Alekseyevskiy & $\mathrm{y}=\mathrm{S} \times(1.485866+1.045356 \times$ Sh.rep $) \times \mathrm{E}$ \\
Novosheshmiskiy & $\mathrm{y}=\mathrm{S} \times(0.962438+1.1479 \times$ Sh.rep $) \times \mathrm{E}$ \\
\hline
\end{tabular}

\section{Conclusion}

Thus, planning the electricity consumption basing on trend-season models takes into account the factual conditions of educational organizations' functioning and allows to reveal the endogenous and exogenous factors of environment, which influence the electricity consumption, allowing to make efficient managerial decisions.

\section{Acknowledgement}

We are grateful to the Heads of Departments on Education and Heads of the researched municipal districts for the provided materials and assistance in informational support of the research.

\section{Author's Contributions}

Nailya Yakupova: Elaboration of the research plan and choosing the research topic.

Rezeda Kundakchyan: Participation in constructing econometric models and checking the reliability of the obtained data.

Roza Andreeva: Consultations on planning the expenditures of educational establishments of municipal districts.

Aleksey Andreev: Carrying out calculations and constructing econometric models.

\section{Ethics}

The article is original and contains unpublished material. The corresponding author confirms that all of other authors have read and approved the manuscript and no ethical Issues involved.

\section{References}

Bashirov, M.G., 2004. Economics of electricity consumption in industry: Tutorial for universities. Ufa: UGNTU.

Winnie, H., 2011. With Post-its and checklists, schools cut their energy bills. The New York Times Company.

IAEA, 2005. Energy indicators for sustainable development: Guidelines and methodologies. IAEA.

EIA, 2014. Annual energy outlook 2014 with projections to 2040. U.S. Energy Information Administration.

David, L.F. and B. Ivan, 2012. The Politics of Environmental Policy in Russia. 1st Edn., Edward Elgar Publishing, Cheltenham, ISBN-10: 0857938517, pp: 189.

Mkhitaryan, V.S., 2005. Statistics. 1st Edn., Economist, Moscow, pp: 671.

Nazarov, M.G., 2000. A Course in Social-Economic Statistics. 1st Edn., Finstatinform, Unity-Dana, Moscow, pp: 771.

Osipov, A.L. and V.N. Khrapov, 2002. Econometrics: Academic-Methodological Complex for Distant Learning. 1st Edn., SibAGS, Novosibirsk, pp: 172. 
Florax, R.J.G.M., H.L.F. De Groot and P. Mulder, 2011. Improving Energy Efficiency through Technology: Trends, Investment Behaviour and Policy Design. Edward Elgar Publishing, Cheltenham, 1st Edn., ISBN-10: 0857930605, pp: 352.

Lee, S. and M. Stephen, 1992. Energy Efficiency and Human Activity: Past Trends, Future Prospects. 1st Edn., Cambridge University Press, Cambridge, ISBN-10: 0521432979, pp: 385.

Kai, S., 1999. Green Budget Reform in Europe: Countries at the Forefront: With 20 Figures and 142 Tables. 1st Edn., Springer Science and Business Media, Berlin, ISBN-10: 354064718X, pp: 443.

Sgroi, F., S. Tudisca, A.M. Di Trapani, R. Testa and R. Squatrito, 2014. Efficacy and efficiency of Italian energy policy: The case of PV systems in greenhouse farms. Energies, 7: 3985-4001.

DOI: $10.3390 /$ en7063985
Suehiro, S., 2007. Energy intensity of a GDP as an index of energy conservation. Institute of Energy Economics, Japan.

Tudisca, S., A.M. Di Trapani, F. Sgroi, R. Testa and R. Squatrito, 2013. Economic analysis of PV systems on buildings in Sicilian farms. Renewable Sustainable Energy Rev., 28: 691-701. DOI: 10.1016/j.rser.2013.08.035

Yakupova, N.M., A.V. Andreev and L.S. Sabitov, 2015. Assessment methods of the efficiency and performance of energy use in the public sphere. Asian Social Sci. DOI: 10.5539/ass.v11n11p104 